\title{
Paradigmatic status of an endo- and exoglucanase and its effect on crystalline cellulose degradation
}

\author{
Sarah Moraïs ${ }^{1,2}$, Yoav Barak ${ }^{1,3}$, Raphael Lamed ${ }^{4}$, David B Wilson ${ }^{5}$, Qi Xu' ${ }^{6}$, Michael E Himmel ${ }^{6}$ and Edward A Bayer ${ }^{1 *}$
}

\begin{abstract}
Background: Microorganisms employ a multiplicity of enzymes to efficiently degrade the composite structure of plant cell wall cellulosic polysaccharides. These remarkable enzyme systems include glycoside hydrolases (cellulases, hemicellulases), polysaccharide lyases, and the carbohydrate esterases. To accomplish this challenging task, several strategies are commonly observed either separately or in combination. These include free enzyme systems, multifunctional enzymes, and multi-enzyme self-assembled designer cellulosome complexes.

Results: In order to compare these different paradigms, we employed a synthetic biology approach to convert two different cellulases from the free enzymatic system of the well-studied bacterium, Thermobifida fusca, into bifunctional enzymes with different modular architectures. We then examined their performance compared to those of the combined parental free-enzyme and equivalent designer-cellulosome systems. The results showed that the cellulolytic activity displayed by the different architectures of the bifunctional enzymes was somewhat inferior to that of the wild-type free enzyme system.
\end{abstract}

Conclusions: The activity exhibited by the designer cellulosome system was equal or superior to that of the free system, presumably reflecting the combined proximity of the enzymes and high flexibility of the designer cellulosome components, thus enabling efficient enzymatic activity of the catalytic modules.

Keywords: Bifunctional cellulase, Thermobifida fusca, Enzyme paradigm

\section{Background}

In nature, three dominant microbial paradigms for enzymatic deconstruction of plant cell walls have been observed [1]. Free enzymes, multifunctional enzymes and multi-enzyme complexes (cellulosomes) are common configurations of microbial cellulase systems.

Glycoside hydrolases have been classified thus far in 130 different families [2], which commonly contain a catalytic module that cleaves the glycoside bond and (frequently) a carbohydrate-binding module (CBM) that targets the enzyme to the polysaccharide substrate, and, in many cases, additional types of ancillary modules. Cellulases include endo- and exo-acting enzymes and $\beta$-D-glucosidases, which work synergistically to

\footnotetext{
* Correspondence: ed.bayer@weizmann.ac.il

'Department of Biological Chemistry, The Weizmann Institute of Science, Rehovot, Israel

Full list of author information is available at the end of the article
}

hydrolyze the recalcitrant crystalline cellulose microfibrils of the plant cell wall.

Cellulosomes were discovered in 1983 [3-5] and are composed of non-catalytic scaffoldins, which contain a carbohydrate-binding module (CBM) for substrate targeting, as well as multiple cohesin modules for integrating dockerin-bearing enzymatic subunits to form a multi-component complex. The intermodular cohesindockerin interaction dictates the assembly of the cellulosome complex. It is believed that synergistic action is achieved by a combination of substrate-targeting and proximity effects whereby the set of cellulosomal enzymes is collectively concentrated at defined sites on the cellulosic substrate.

A third enzyme paradigm has also emerged: multifunctional enzymes are composed of two or more catalytic modules important for the degradation of plant cell walls [6-11]. They generally contain one or several CBMs and are thus very high-molecular-weight proteins. Dockerin- 
bearing multifunctional enzymes may also be incorporated into cellulosomes. The presence of several catalytic modules in the same polypeptide chain would seem to indicate that their enforced proximity would account for an enhanced concerted action on cellulosic substrates. To date, four different types of multifunctional enzymes have been described: cellulase-cellulase, hemicellulase-hemicellulase, hemicellulase-cellulase and hemicellulase-carbohydrate esterase systems [1]. Cellulase-cellulase multifunctional enzymes observed to date present a variety of modular architectures and include combination of two catalytic modules (GH6 with GH12, GH9 with GH48, GH5 with GH12 or GH5 with GH6) with a minimum of one CBM (from families 2, 3, 5 and 10) and could contain supplementary ancillary modules such as FN3-like modules $[1,12]$.

The benefits of each strategy have been the subject of many research projects in the field, but remain as yet unclear. The comparison between free enzymatic and cellulosomal systems has been addressed in a number of recent studies [13-23], and it appears that the cellulosomal paradigm offers advantages in deconstructing insoluble cellulosic substrates relative to free enzyme systems.

Another interesting attempt to increase enzyme synergism and compare enzyme paradigms was reported recently in the form of multifunctional enzyme conjugates [24,25]. These authors observed an increase in degradation of natural substrates, upon fusing two or three complementary xylan-degrading activities (xylanase, arabinofuranosidase and xylosidase) into the same polypeptide chain. Other multifunctional enzyme chimeras have been created successfully and revealed promising combined activities [26-28].

Nevertheless, comparison between the three major enzyme paradigms has not been reported in the literature. In this communication, we describe the use of the wellcharacterized cellulolytic system of Thermobifida fusca as a model to compare the performance of the three enzyme paradigms. T. fusca possesses a limited set of only six cellulases and does not produce multifunctional enzymes. It thus represents an excellent system to prepare a variety of free and complexed cellulase systems, using the catalytic modules derived from this bacterium. In previous studies $[16,18,19,21,22]$, we have employed synthetic biology approaches to compare both free $T$. fusca enzymes and their respective engineered designer cellulosomes. One advantage of the T. fusca system is that even though its enzymes are not cellulosomal, a dockerin module can be readily grafted onto the parent enzyme by replacing the native CBM; the chimaeric enzyme can then be assembled into a complementary scaffoldin to form a designer cellulosome.

In the present study, we compared the combined synergistic action of two T. fusca cellulases: (i) in their free state (the wild-type system), (ii) as bifunctional enzymes in a single polypeptide chain (i.e., to mimic the natural multifunctional cellulase-cellulase system) and (iii) as dockerinbearing enzymes attached to a scaffoldin in the cellulosomal mode. In a related work [17], a designer cellulosome composed of two T. fusca cellulases (endoglucanase Cel5A and exoglucanase Cel48A) converted to the cellulosomal mode was demonstrated to be more efficient in degrading the crystalline cellulose substrate compared to a mixture of the respective wild-type enzymes. The same two cellulases were therefore selected to further compare their performance as bifunctional enzymes.

This report describes a set of bifunctional enzymes produced by gene fusion of catalytic modules together with one or two CBMs. The Cel48A exoglucanase and the Cel5A endoglucanase from $T$. fusca were combined to produce diverse geometrical arrangements, and the resulting chimeras were tested for their activity on microcrystalline cellulose. The results were compared to the parallel action of the two wild-type enzymes and the corresponding designer cellulosome bearing the converted dockerin-containing chimaeras $(b-48 \mathrm{~A}$ and $f-5 \mathrm{~A})$.

\section{Results}

\section{Construction and expression of recombinant proteins}

The recombinant proteins designed for use in this study are shown schematically in Figure 1. The enzymes used for this work were based on the wild-type $T$. fusca endoglucanase Cel5A and exoglucanase Cel48A. The CBMs of both enzymes are located at the $N$-terminus of the protein in the native state, belong to family 2 and are able to bind microcrystalline and amorphous cellulosic substrates in a similar manner [29-31]. Several modifications of the original wild-type enzymes were designed within the context of the objectives of the study as will be described in the following paragraphs.

First, the CBMs of the two enzymes were interchanged to form the $\mathrm{CBM}(48)-5$ and $\mathrm{CBM}(5)-48$ chimaeras, respectively, in order to explore whether the origin of the CBM influences the enzymatic activities of the cellulases in the free mode.

Next, a series of bifunctional enzyme chimaeras were designed, which contained permutations of both the family 5 and family 48 catalytic module together with the family 2 CBM from the wild-type Cel5A or Cel48A (or both), thus generating the CBM-5-48, CBM-48-5, 5-CBM-48 and CBM-5-CBM-48 bifunctional enzymes (Figure 1).

In addition, the two cellulases were converted to the cellulosomal mode, whereby: (i) the endoglucanase $f-5 \mathrm{~A}$, comprised two fused modules the catalytic module of the family-5 endoglucanase Cel5A from T. fusca, and a dockerin at the $N$-terminus from the $R$. flavefaciens ScaA scaffoldin [32], and (ii) the exoglucanase, $b-48 \mathrm{~A}$, comprised the catalytic module of $T$. fusca exoglucanase Cel48A ligated with a dockerin from the B. cellulosolvens 


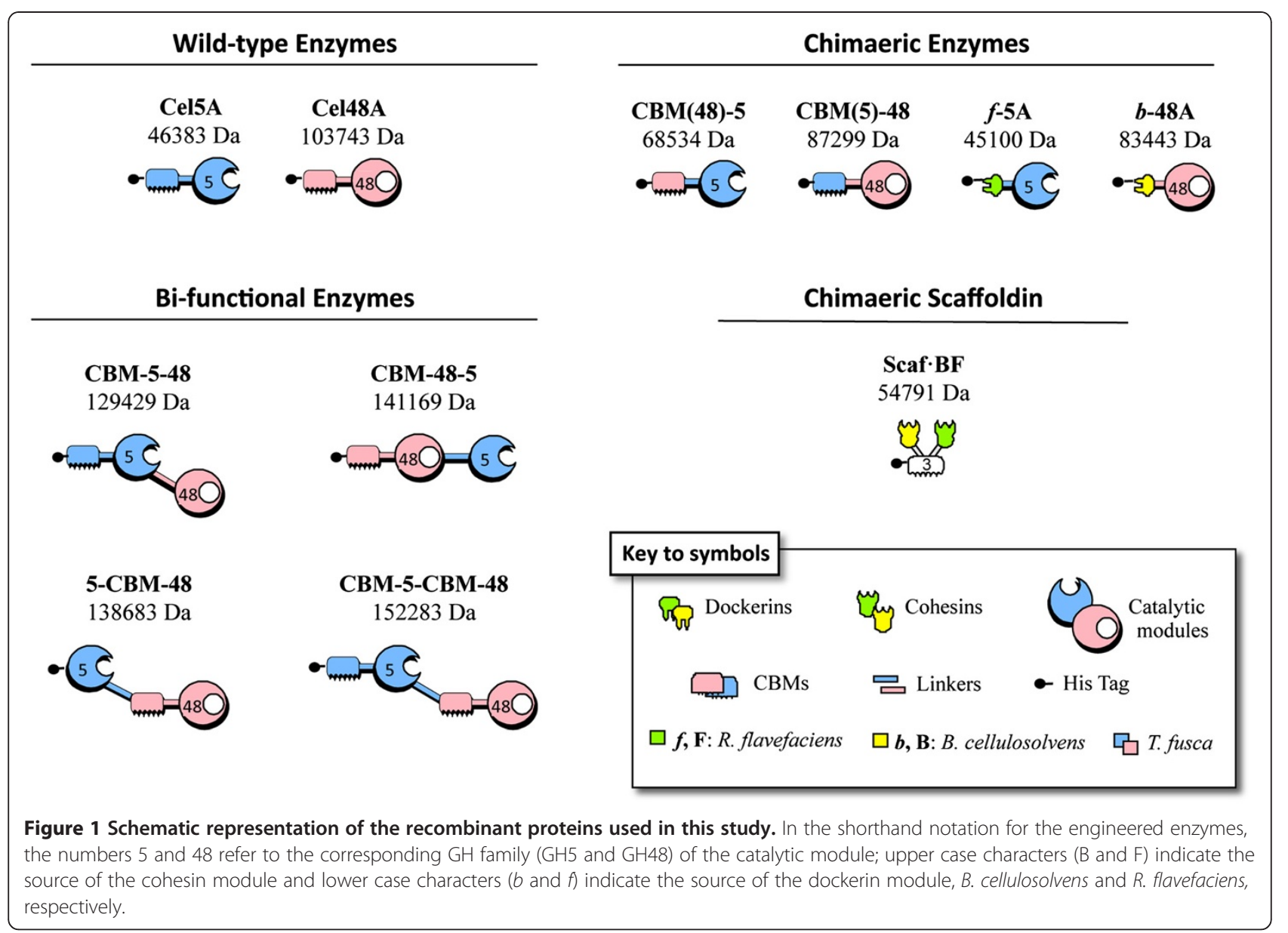

ScaA scaffoldin, also at the $N$-terminus. The bivalent chimaeric scaffoldin, Scaf.BF was designed to carry two cohesins of divergent specificity, matching those of the latter dockerins, thereby enabling selective incorporation of the two cellulases into a designer cellulosome. The specific modules that comprise the construct are as follows: cohesin 3 from scaffoldin B of B. cellulosolvens (designated B), the family 3a CBM from C. thermocellum, which binds strongly to cellulose [33], and cohesin 1 from $R$. flavefaciens scaffoldin B (designated F) [32].

\section{Cohesin-dockerin specificity}

The specificity of the cohesins for the chimaeric dockerinbearing enzymes was examined semi-quantitatively by a sensitive enzyme-linked affinity assay in microtiter plates [34]. Both cohesins in the chimaeric Scaf.BF specifically bound to their respective dockerin and did not bind (or bound very poorly) to other non-matching dockerin-bearing proteins (data not shown). The results were similar to those demonstrated in previous reports $[17,18]$. The scaffoldin-borne cohesins bound to their matching dockerins just as efficiently as the individual, monovalent (single-cohesin) scaffoldins, indicating that the binding capabilities of the scaffoldin were reliable and selective. All specific cohesin-dockerin interactions were of similar intensity, indicating that similar amounts of protein were bound in each well, supporting a cohesin:dockerin molar equivalent of 1:1.

\section{Complex formation}

Designer cellulosome complex formation was tested by non-denaturing PAGE. Denaturing PAGE was used as a control for verification of sample content. Predetermined stoichiometric mixtures of the enzymes and the scaffoldin resulted in a single band with altered mobility (band strengthened and shifted), indicating that complete or near-complete complexation was achieved in all cases (data not shown). The quality of the assembly of the designer cellulosome components was similar to those of earlier publications $[21,35]$.

\section{CBM interplay}

Interchanging the Cel48A and Cel5A family-2 CBMs did not significantly affect their enzymatic activities on microcrystalline cellulose (Avicel) (Figure 2A). Combinations of the two enzymes, either wild-type, chimaeras or mixture of wild-type and chimaera, exhibited very 

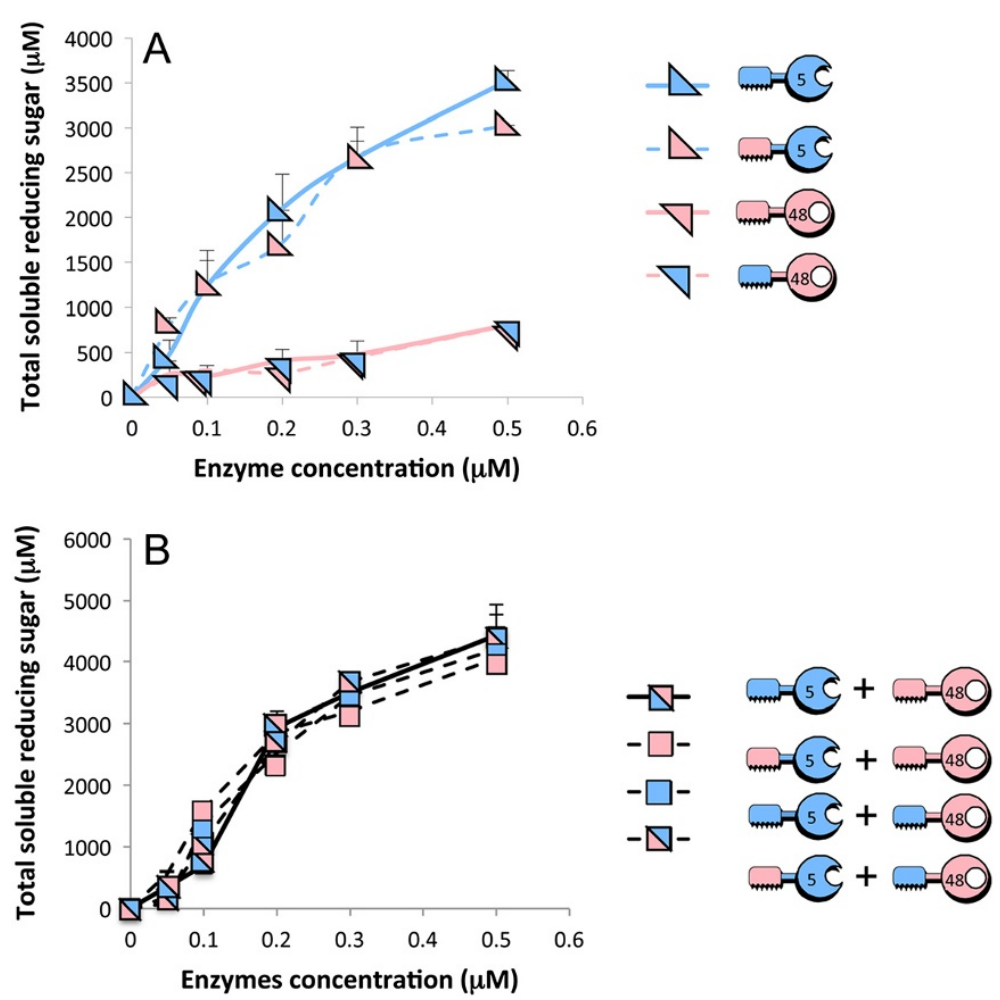

Figure 2 Influence of CBM source on cellulase activities. A. Kinetics studies on microcrystalline cellulose hydrolysis by the wild-type cellulases versus the chimaeric cellulases. B. Kinetics studies on microcrystalline cellulose hydrolysis by the combination of wild-type versus chimeric cellulases versus mixtures of wild-type and chimaeric enzymes. For convenience, keys and pictograms of the various enzymes are provided. For free enzymes combination, micromolar enzyme concentrations correspond to each one of the enzymes. Triplicates of each reaction were carried out, and standard deviations are indicated.

similar enzymatic activities on microcrystalline cellulose as well (Figure 2B). Thus, the choice of using the family2 CBM originating from Cel48A or Cel5A during the design of bifunctional enzymes would not be expected to affect their combined activities as bifunctional enzymes. Little or no synergy between the wild-type Cel5A endoglucanase and Cel48A exoglucanase could be observed (Figure 2A and 2B) in line with previous reports $[29,36]$.

\section{Enzymatic activity of the bifunctional enzymes}

The enzymatic activities on Avicel of the three bifunctional enzymes, CBM-5-48, 5-CBM-48 and CBM-48-5, were compared to the activity of the mixture of the wild-type enzymes Cel48A and Cel5A (Figure 3). The bifunctional enzymes, 5-CBM-48 and CBM-48-5, demonstrated markedly reduced activities relative to the wild-type enzymes (two-fold reduction), whereas CBM5-48 exhibited only a moderate reduction in activity ( $\sim 15 \%$ reduction at the highest concentrations) towards the wild-type enzyme mixture. These results suggest that within the context of a bifunctional enzyme the position of each module (catalytic module and CBM) has an influence on its overall enzymatic activity.

\section{Multi-modular enzyme design versus the designer cellulosome approach}

The bifunctional enzyme CBM-5-CBM-48 exhibited a $\sim 20 \%$ reduction in enzymatic activity at the highest concentrations on Avicel compared to CBM-5-48 (Figure 4), suggesting that the addition of a second CBM decreased the observed degradation of the microcrystalline cellulosic substrate. The mixture of free wild-type enzymes (shown in Figure 3) was found to be more effective than any of the bifunctional chimaeras, and the designer cellulosome exhibited a minor but statistically significant enhancement $(\sim 8 \%)$ in enzymatic activity relative to that of the free wild-type enzymes.

\section{Discussion}

In past studies, we have succeeded in "domesticating" the cellulases and xylanases of the well-characterized free enzymatic system of $T$. fusca to work in the cellulosomal mode [16-22]. In the present communication, we examined the conversion of these enzymes into the multifunctional mode, by integrating the catalytic modules of two prominent cellulases of the T. fusca system, a family 5 endoglucanase and a family 48 exoglucanase, into a single polypeptide chain. The two cellulases, Cel5A and Cel48A, 


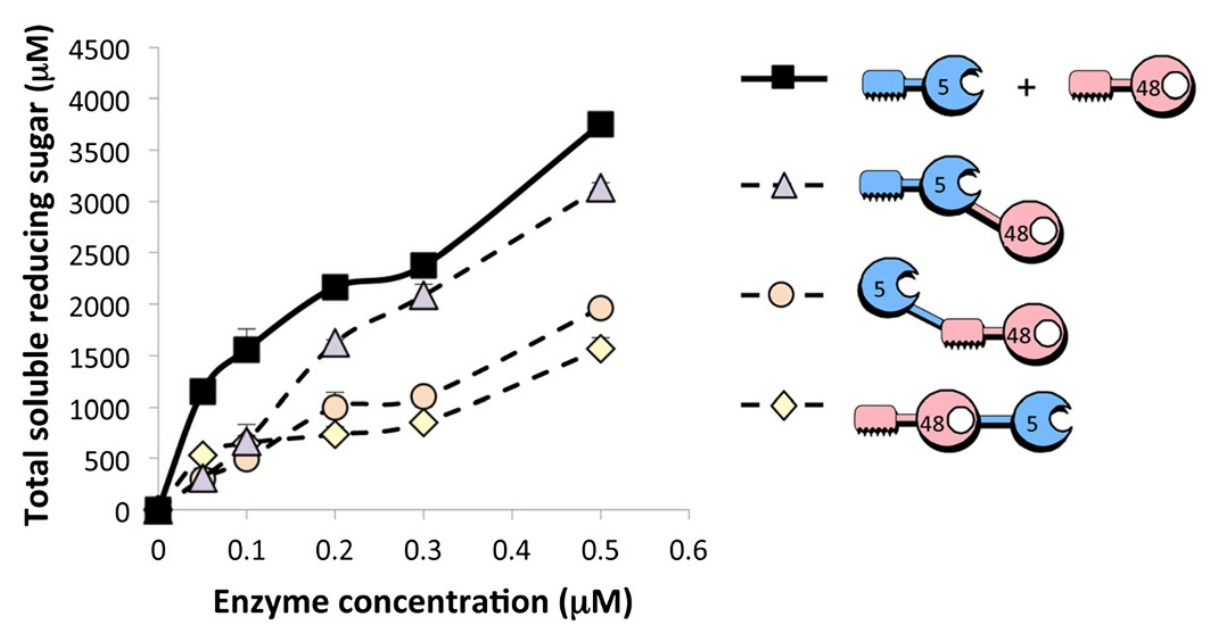

Figure 3 Kinetics studies on microcrystalline cellulose hydrolysis by the wild-type cellulases versus the bifunctional cellulases. For convenience, keys and pictograms of the various enzymes are provided. The pictograms denoting the indicated enzymes are defined in Figure 1. For free enzymes combination, micromolar enzyme concentrations correspond to each one of the enzymes. Triplicates of each reaction were carried out, and standard deviations are indicated.

respectively, have been selected for their known synergistic cooperation on cellulosic substrates [17]. Moreover, both of these GH families occur frequently in bifunctional endo-/exo-type enzymes, despite the fact that combined GH48 and GH5 catalytic modules have yet to be described as collective components of a natural multifunctional enzyme system $[1,12,37,38]$. Our previous research with these two enzymes [17], however, has demonstrated their compatibility in both the free and cellulosomal modes, which forms solid basis for their combined comparative evaluation in the bifunctional state.
In designing the components of the chimaeric and bifunctional enzymes, careful attention was paid to the precise grafting of the component parts according to predetermined criteria in order to form the final product. In this context, each catalytic module was cloned as a unit together with its intact wild-type linker to which the desired component (CBM, dockerin or enzyme) was appended. When necessary, i.e., for design of 5-CBM-48 and CBM-5-CBM-48, the entire linker of Cel5A was used and inserted at the $C$-terminus of the GH5 catalytic module.

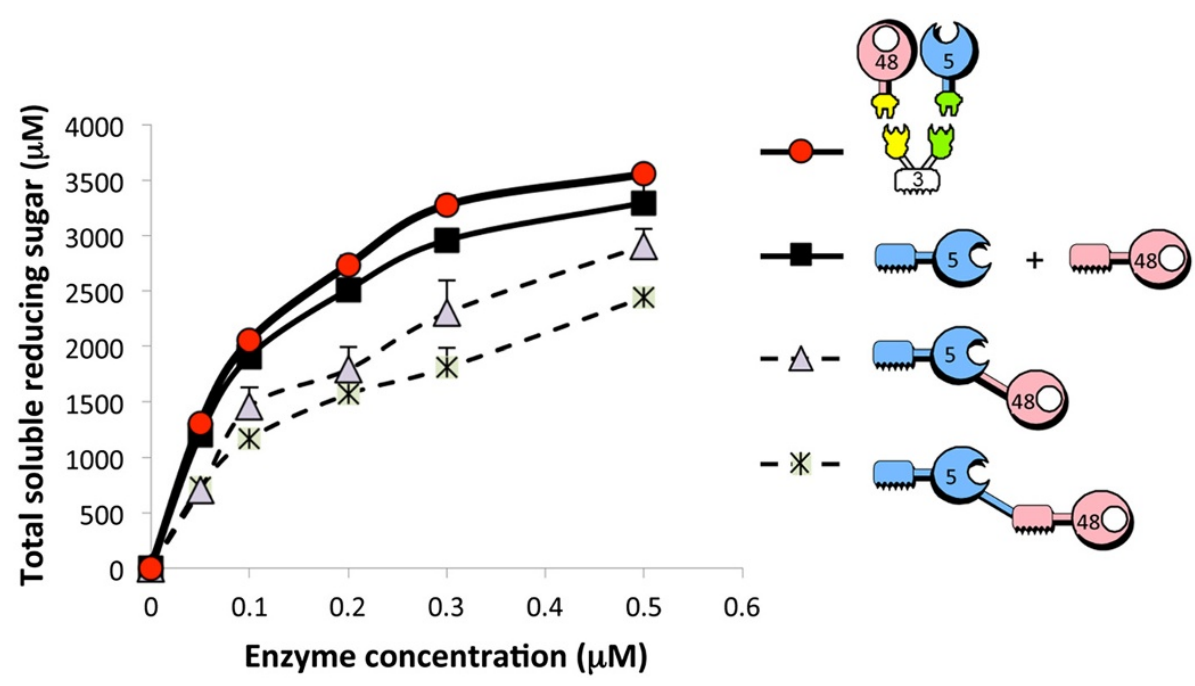

Figure 4 Kinetics studies on microcrystalline cellulose hydrolysis by the wild-type cellulases versus the bifunctional cellulases and the designer cellulosomes. For convenience, keys and pictograms (defined in Figure 1) of the various enzymes are provided. For free enzymes combination, micromolar enzyme concentrations correspond to each one of the enzymes. Triplicates of each reaction were carried out, and standard deviations are indicated. 
Multifunctional enzymes observed in nature display CBMs belonging to various CBM families including family 2 [1], thus supporting integration of the original family-2 CBMs of the cellulases into the bifunctional chimaeras designed in this work. Interchanging the CBM2 of Cel5A and Cel48A revealed that both CBM2s confer similar levels of enzymatic activities to the catalytic modules either as an intact free enzyme or in combination in the bifunctional state. Therefore, the CBM2 originating from either Cel5A or Cel48A could be used as a viable component in designing a desired bifunctional enzyme without further consideration. The number and position of CBMs in the multifunctional enzyme has an effect on the enzymatic activity of the given chimaera. An inhibitory effect on cellulose degradation was thus observed when two copies of the family-2 CBM were present on the bifunctional enzyme. A similar effect was reported earlier for family $3 \mathrm{CBMs}$ as chimaeric scaffoldin components in designer cellulosomes [14,39]. Nevertheless, the inhibitory effect shown in the present article may not reflect a simple excess of substratetargeting modules, which may impede the dynamic and concerted action of the two enzymes on the substrate. The data for the bifunctional enzymes shown in Figures 3 and 4 revealed that the position of the various modules on the polypeptide chain is of critical importance to the activity of the enzyme. Thus, it appears that the bifunctional enzyme with the endoglucanase on the $N$-terminus (CBM-5-48) exhibits enhanced cellulolytic activity compared to the $N$-terminally positioned exoglucanase (CBM-48-5). Moreover, the CBM located on the $N$-terminus of the GH5 appears to be critically important to activity, since in its absence the respective chimaera (5-CBM-48) shows markedly reduced levels of cellulose degradation.

The matching set of enzymes and associated components designed for this study allowed us to compare the enzymatic activity on cellulose of the three enzyme paradigms, (i) the wild-type enzymes, (ii) the respective dockerin-containing chimaeras converted to cellulosomal modes and (iii) the enzymes converted to the bifunctional mode. In all cases, the components contain the same GH5 endoglucanase and GH48 exoglucanase. Bifunctional and cellulosomal systems would presumably act with enhanced synergy (in comparison to the wildtype free enzyme system) because the proximity of the enzymes to each other would allow the newly formed free chain ends, created by the endoglucanases, to be exposed to processive action by the exoglucanase. However, in view of our results, only the designer cellulosome paradigm demonstrated minor levels of enhanced enzymatic activity relative to the free enzymes. Possible explanations could be that designer cellulosomes have a higher flexibility that enables more efficient enzymatic activity or that the structural conformations of the catalytic modules upon their fusion affected their enzymatic abilities. In past studies, designer cellulosomes composed of dockerin-bearing converted enzymes from $T$. fusca achieved optimal levels of degradation, which surpassed the activity of the free wild-type enzymes on cellulosic substrates [16-18,20-23].

It appears that designing effective multifunctional enzymes is challenging as the position of the component parts and presumably the length and composition of the linkers will have an impact on the overall activity of the resulting protein. In native multifunctional enzymes, the exact spacing and positioning of the components is the product of lengthy evolutionary selection to optimize synergy between catalytic modules. As a result, the preservation or improvement of the enzymatic characteristics in multifunctional chimaeras may be more difficult than enhancing the enzymatic performance of individual components.

\section{Conclusions}

Although promising fusion proteins have been demonstrated in previous works [26-28], and considerable benefits such as efficient reactivity due to intramolecular synergy, easier optimization of physical charaterization (including $\mathrm{pH}$ and temperature) and production of a single protein have been discussed; knowledge of the basic mechanisms is still lacking in this field. In addition, naturally occurring multifunctional enzymes are limited to small numbers of enzymes and their existence as functional components on the same polypeptide chain implies that these enzymes would be expected to work in concert. On the other hand, the presence of two different enzymatic activities on a single polypeptide chain also implies that these activities are confined to equimolar ratios, which are usually sub-optimal [40-44].

Engineering multifunctional enzymes deserves continued research efforts as the formation of multifunctional enzymes could be regarded as the naturally occurring fusion of various complementary sets of catalytic and other modules to perform their respective functions in the hydrolysis of plant cell walls. In addition, both multifunctional enzymes and free enzymes occur together in the certain cellulosome-producing bacterial species, such as Clostridium thermocellum or Ruminococcus flavefaciens $[6,7,10,45-48]$, thus implying that the cooperative action of the different enzymatic paradigms serves to benefit the overall efficiency of plant cell wall degradation.

\section{Methods}

\section{Cloning}

Wild-type, chimaeric enzymes and recombinant scaffoldins Cel5A, Cel48A, $b-48 \mathrm{~A}, f-5 \mathrm{~A}$, and Scaf.BF were cloned as described previously $[21,29,30]$. 
Chimaeric enzymes CBM(48)-5, CBM(5)-48, CBM-548, 5-CBM-48, CBM-48-5 and CBM-5-CBM-48 plasmids were assembled from catalytic modules and CBM, cloned from $T$. fusca genomic DNA. Family 5 catalytic module was amplified using primers $5^{\prime}$-NNNNNNGAC GAAGGCTCCGAGCCGGGCGGCCCC-3' and $5^{\prime}$-NNN NNNTCAGGACTGGAGCTTGCTCC-3' (where NNNNN represents 4 to 6 random nucleotides that appear before the appropriate restriction site); family 48 catalytic module using $5^{\prime}$-NNNNNNCCACCCACCGTCCGCGT GCCGCAGGG-3' and 5'-NNNNNNTCAGGGA GCTC CGGCCCCGAACAGT-3'; family-2 CBM from Cel5A using $5^{\prime}$-NNNNNNGCTGGTCTCACCGCCACA GTCA$3^{\prime}$ and $5^{\prime}$-GTGCCGGTGCCGGGCTGCGTGC-3' and family-2 CBM from Cel48A using $5^{\prime}$-NNNNN The different modules were assembled in linearized pET28a to form the plasmids.

All enzyme constructs were designed to contain a Histag for the subsequent purification. PCR reactions were performed using ABgene Reddymix x2 (Advanced Biotechnologies Ltd., United Kingdom) and DNA samples were purified using a HiYield ${ }^{\mathrm{TM}}$ Gel/PCR Fragments Extraction Kit (Real Biotech Corporation, RBC, Taiwan).

\section{Protein expression and purification}

Wild-type, chimaeric enzymes and recombinant scaffoldin Cel5A, Cel48A, $b-48 \mathrm{~A}, f-5 \mathrm{~A}$, and Scaf-BF were prepared as described previously $[21,29,30]$. Chimaeric enzymes CBM(48)-5, CBM(5)-48, CBM-5-48, 5-CBM48, CBM-48-5 and CBM-5-CBM-48 plasmids were expressed in E. coli BL21 (IDE3) pLysS cells and purified on a Ni-NTA column (Qiagen), as reported earlier [19]. Scaffoldin, Scaf.BF, was expressed and purified on phosphoric acid swollen cellulose $7.5 \mathrm{mg} \mathrm{mL}^{-1} \mathrm{pH} 7$ (PASC) according to the previously described methodology [49]. Purity of the recombinant proteins was tested by SDSPAGE on $12 \%$ acrylamide gels. The concentration of each purified protein was estimated by absorbance (280 $\mathrm{nm}$ ) based on the known amino acid composition of the protein using the Protparam tool (http://www.expasy. org/tools/protparam.html). Proteins were stored in 50\% (v/v) glycerol at $-20^{\circ} \mathrm{C}$.

\section{Affinity-based ELISA}

The matching fusion-protein procedure of Barak and coworkers $[19,34]$ was followed to determine cohesindockerin specificity.

\section{Non-denaturing PAGE}

To check the full interaction between scaffoldin and enzymes, a differential mobility assay on non-denaturing gels was used. In a $30 \mu \mathrm{L}$ reaction (in which $15 \mu \mathrm{L}$ of Tris Buffer Saline pH 7.4 (TBS) buffer, supplemented with $10 \mathrm{mM} \mathrm{CaCl}_{2}$ and $0.05 \%$ Tween 20), 4 to $8 \mu \mathrm{g}$ of each protein were added in an equimolar manner. The $1.5 \mathrm{~mL}$ tubes were incubated $1.5 \mathrm{~h}$ at $37^{\circ} \mathrm{C}$. Sample buffer $(7.5 \mu \mathrm{L}$, in the absence of SDS) was added to $15 \mu \mathrm{L}$ of the reaction mixture, and the samples were loaded onto non-denaturing gels (4.3\%-stacking/9\%-separating phase). A parallel SDS-PAGE gel (10\%) was performed on the remaining $15 \mu \mathrm{L}$ sample.

\section{Enzymatic activity}

The enzymes ( 0 to $0.6 \mu \mathrm{M})$ were tested in $200 \mu \mathrm{L}$ final volume, containing $40 \mu \mathrm{L}$ microcrystalline cellulose $10 \%$ (Avicel, FMC Biopolymer (Philadelphia, PA, USA)), 0.8 $\mu \mathrm{L}$ EDTA $(0.5 \mathrm{M}), 1.2 \mu \mathrm{L}$ of $\mathrm{CaCl}_{2}(2 \mathrm{M})$ and $20 \mu \mathrm{L}$ of acetate buffer $(0.5 \mathrm{M}, \mathrm{pH} 5)$. The $1.5 \mathrm{~mL}$ tubes were incubated for $18 \mathrm{~h}$ at $50^{\circ} \mathrm{C}$ under shaking conditions, and the reaction was terminated by immersion of the tube in ice water. The samples were then centrifuged for $10 \mathrm{~min}$, at $14,000 \mathrm{rpm}$ and $4^{\circ} \mathrm{C}, 100 \mu \mathrm{L}$ of the supernatant was added to $150 \mu \mathrm{L}$ dinitrosalicylic acid reagent (DNS) [50], and the mixtures were boiled for $10 \mathrm{~min}$. The absorbance then was measured at $540 \mathrm{~nm}$. Enzymatic activity was calculated using a glucose standard curve and was expressed in $\infty$ moles of glucose equivalents (reducing sugar) per minute. Dockerin-containing enzymes were subjected to $2 \mathrm{~h}$ incubation $\left(37^{\circ} \mathrm{C}\right.$, in the absence of substrate) in the presence of equimolar concentrations of scaffoldin, prior to assay for binding interaction. All assays were performed in triplicate.

\section{Abbreviations}

CBM: Carbohydrate-binding module; GH: Glycoside hydrolase; DNS: Dinitrosalicylic acid; PASC: Phosphoric acid swollen cellulose; TBS: Tris buffer saline.

\section{Competing interests}

The authors declare that they have no competing interests.

\section{Authors' contributions}

SM designed and carried out the experiments, analyzed results and wrote the manuscript. YB, DBW and QX assisted in the experimental design and reviewed the manuscript. $M E H$ and EAB coordinated the study and reviewed the manuscript. All authors read and approved the final manuscript.

\section{Acknowledgements}

S.M. greatly appreciates a scholarship received from the Ministry of Immigrant Absorption, Jerusalem, Israel. This research was supported by grants from the United States-Israel Binational Science Foundation (BSF), Jerusalem, Israel, by the Weizmann Institute of Science Alternative Energy Research Initiative (AERI) and the Helmsley Foundation, the F. Warren Hellman I-SAEF Grant in support of alternative energy research in Israel to EAB from the Israel Strategic Alternative Energy Foundation (I-SAEF), a grant to $E A B$ and RL from the Israel Ministry of Science (IMOS), by grants (966/09, 159/07 and 24/11 to EAB and RL) by the Israel Science Foundation and establishment of an Israeli Center of Research Excellence (I-CORE Center No. $152 / 11, E A B)$ managed by the Israel Science Foundation. This work was also supported by a subcontract from NREL funded by the U.S. DOE Office of the Biomass Program. E.A.B. is the incumbent of The Maynard I. and Elaine Wishner Chair of Bio-organic Chemistry.

\section{Author details}

'Department of Biological Chemistry, The Weizmann Institute of Science, Rehovot, Israel. 'Faculty of Agricultural, Food and Environmental Quality 
Sciences, The Hebrew University of Jerusalem, P.O. Box 12, Rehovot 76100, Israel. ${ }^{3}$ Chemical Research Support, The Weizmann Institute of Science, Rehovot 76100, Israel. ${ }^{4}$ Department of Molecular Microbiology and Biotechnology, Tel Aviv University, Ramat Aviv 69978, Israel. ${ }^{5}$ Department of Molecular Biology and Genetics, Cornell University, Ithaca, NY 14853, USA. ${ }^{6}$ Biosciences Center, National Renewable Energy Laboratory (NREL) and BioEnergy Science Center (BESC), Golden, CO, USA.

Received: 30 August 2012 Accepted: 19 October 2012

Published: 24 October 2012

\section{References}

1. Himmel M, Xu Q, Luo Y, Ding S, Lamed R, Bayer E: Microbial enzyme systems for biomass conversion: emerging paradigms. Biofuels 2010 1:323-341.

2. Cantarel BL, Coutinho PM, Rancurel C, Bernard T, Lombard V, Henrissat B: The carbohydrate-active enZymes database (CAZy): an expert resource for glycogenomics. Nucleic Acids Res 2009, 37:D233-D238.

3. Lamed R, Setter E, Bayer EA: Characterization of a cellulose-binding, cellulase-containing complex in clostridium thermocellum. J Bacterio/ 1983, 156:828-836.

4. Lamed R, Setter E, Kenig R, Bayer EA: The cellulosome - a discrete cell surface organelle of clostridium thermocellum which exhibits separate antigenic, cellulose-binding and various cellulolytic activities. Biotechnol Bioeng Symp 1983, 13:163-181.

5. Bayer EA, Kenig R, Lamed R: Adherence of clostridium thermocellum to cellulose. J Bacteriol 1983, 156:818-827.

6. Garcia-Campayo V, McCrae SI, Zhang JX, Flint HJ, Wood TM: Mode of action, kinetic properties and physicochemical characterization of two different domains of a bifunctional (1->4)-beta-D-xylanase from ruminococcus flavefaciens expressed separately in Escherichia coli. Biochem J 1993, 296(Pt 1):235-243.

7. Najmudin S, Guerreiro Cl, Ferreira LM, Romao MJ, Fontes CM, Prates JA: Overexpression, purification and crystallization of the two C-terminal domains of the bifunctional cellulase ctCel9D-Cel44A from clostridium thermocellum. Acta Crystallogr Sect F Struct Biol Cryst Commun 2005, 61:1043-1045.

8. Sakka K, Yoshikawa K, Kojima Y, Karita S, Ohmiya K, Shimada K: Nucleotide sequence of the clostridium stercorarium xylA gene encoding a bifunctional protein with beta-D-xylosidase and alpha-Larabinofuranosidase activities, and properties of the translated product. Biosci Biotechnol Biochem 1993, 57:268-272.

9. Saul DJ, Williams LC, Grayling RA, Chamley LW, Love DR, Bergquist PL: celB, a gene coding for a bifunctional cellulase from the extreme thermophile "Caldocellum saccharolyticum". Appl Environ Microbiol 1990, 56:3117-3124.

10. Zhang JX, Flint HJ: A bifunctional xylanase encoded by the xynA gene of the rumen cellulolytic bacterium ruminococcus flavefaciens 17 comprises two dissimilar domains linked by an asparagine/glutaminerich sequence. Mol Microbiol 1992, 6:1013-1023.

11. Zverlov V, Mahr S, Riedel K, Bronnenmeier K: Properties and gene structure of a bifunctional cellulolytic enzyme (CelA) from the extreme thermophile 'Anaerocellum thermophilum' with separate glycosyl hydrolase family 9 and 48 catalytic domains. Microbiology 1998, 144:457-465.

12. Xu Q, Luo Y, Bu L, Ding S-Y, Lamed R, Bayer EA, Himmel ME: Bulk commodities - industrial enzymes: multifunctional enzyme systems for plant cell wall degradation. In Comprehensive biotechnology. volume 3. 2nd edition. Edited by Moo-Young M, Butler M, Webb C, Moreira A, Bai F. Amsterdam: Elsevier B.V; 2011:15-25

13. Fierobe H-P, Mechaly A, Tardif C, Belaich A, Lamed R, Shoham Y, Belaich J-P, Bayer EA: Design and production of active cellulosome chimeras: Selective incorporation of dockerin-containing enzymes into defined functional complexes. J Biol Chem 2001, 276:21257-21261.

14. Fierobe H-P, Mechaly A, Tardif C, Belaich A, Lamed R, Shoham Y, Belaich J-P, Bayer EA: Designer nanosomes: Selective engineering of dockerincontaining enzymes into chimeric scaffoldins to form defined nanoreactors. In Carbohydrate bioengineering: interdisciplinary approaches. Edited by Teeri TT, Svensson B, Gilbert HJ, Feizi T. Cambridge: The Royal Society of Chemistry; 2002:113-123.

15. Fierobe H-P, Mingardon F, Mechaly A, Belaich A, Rincon MT, Lamed R, Tardif C, Belaich J-P, Bayer EA: Action of designer cellulosomes on homogeneous versus complex substrates: controlled incorporation of three distinct enzymes into a defined tri-functional scaffoldin. J Biol Chem 2005, 280:16325-16334

16. Caspi J, Barak Y, Haimovitz R, Gilary H, Irwin D, Lamed R, Wilson DB, Bayer EA: Thermobifida fusca exoglucanase Cel6B is incompatible with the cellulosomal mode in contrast to endoglucanase Cel6A. Syst Synth Bio 2010, 4:193-201.

17. Caspi J, Barak Y, Haimovitz R, Irwin D, Lamed R, Wilson DB, Bayer EA: Effect of linker length and dockerin position on conversion of a Thermobifida fusca endoglucanase to the cellulosomal mode. Appl Environ Microbiol 2009, 75:7335-7342

18. Caspi J, Irwin D, Lamed R, Fierobe H-P, Wilson DB, Bayer EA: Conversion of noncellulosomal thermobifida fusca free exoglucanases into cellulosomal components: comparative impact on cellulose-degrading activity. J Biotechnol 2008, 135:351-357.

19. Caspi J, Irwin D, Lamed R, Shoham Y, Fierobe H-P, Wilson DB, Bayer EA: Thermobifida fusca family- 6 cellulases as potential designer cellulosome components. Biocatalysis and Biotransformation 2006, 24:3-12

20. Moraïs S, Barak Y, Caspi J, Hadar Y, Lamed R, Shoham Y, Wilson DB, Bayer EA: Contribution of a xylan-binding module to the degradation of a complex cellulosic substrate by designer cellulosomes. Appl Environ Microbiol 2010, 76:3787-3796.

21. Moraïs S, Barak Y, Caspi J, Hadar Y, Lamed R, Shoham Y, Wilson DB, Baye EA: Cellulase-xylanase synergy in designer cellulosomes for enhanced degradation of a complex cellulosic substrate. mBio 2010, 1:e00285-00210

22. Morais S, Barak Y, Hadar Y, Wilson DB, Shoham Y, Lamed R, Bayer EA Assembly of xylanases into designer cellulosomes promotes efficient hydrolysis of the xylan component of a natural recalcitrant cellulosic substrate. mBio 2011, 2:e00233-11.

23. Moraïs S, Heyman A, Barak Y, Caspi J, Wilson DB, Lamed R, Shoseyov O, Bayer EA: Enhanced cellulose degradation by nano-complexed enzymes: synergism between a scaffold-linked exoglucanase and a free endoglucanase. J Biotechnol 2010, 147:205-211.

24. Fan ZM, Wagschal K, Chen W, Montross MD, Lee CC, Yuan L: Multimeric hemicellulases facilitate biomass conversion. Appl Environ Microbiol 2009, 75:1754-1757.

25. Fan ZM, Wagschal K, Lee CC, Kong Q, Shen KA, Maiti IB, Yuan L: The construction and characterization of two xylan-degrading chimeric enzymes. Biotechnol Bioeng 2009, 102:684-692.

26. Hong SY, Lee JS, Cho KM, Math RK, Kim YH, Hong SJ, Cho YU, Kim H, Yun HD: Assembling a novel bifunctional cellulase-xylanase from thermotoga maritima by end-to-end fusion. Biotechnol Lett 2006, 28:1857-1862.

27. Khandeparker R, Numan MT: Bifunctional xylanases and their potential use in biotechnology. J Ind Microbiol Biotechnol 2008, 35:635-644.

28. Lee $\mathrm{HL}$, Chang $\mathrm{CK}$, Teng $\mathrm{KH}$, Liang $\mathrm{PH}$ : Construction and characterization of different fusion proteins between cellulases and beta-glucosidase to improve glucose production and thermostability. Bioresour Technol 2011, 102:3973-3976.

29. Irwin DC, Zhang S, Wilson DB: Cloning, expression and characterization of a family 48 exocellulase, Cel48A, from thermobifida fusca. Eur J Biochem 2000, 267:4988-4997.

30. McGinnis K, Wilson DB: Disulfide arrangement and functional domains of beta-1,4-endoglucanse E5 from thermomonospora fusca. Biochemistry 1993, 32:8157-8161.

31. Jung $H$, Wilson $D B$, Walker $L P$ : Binding and reversibility of thermobifida fusca Cel5A, Cel6B, and Cel48A and their respective catalytic domains to bacterial microcrystalline cellulose. Biotechnol Bioeng 2003, 84:151-159.

32. Ding S-Y, Rincon MT, Lamed R, Martin JC, McCrae SI, Aurilia V, Shoham Y, Bayer EA, Flint HJ: Cellulosomal scaffoldin-like proteins from ruminococcus flavefaciens. J Bacteriol 2001, 183:1945-1953.

33. Morag E, Lapidot A, Govorko D, Lamed R, Wilchek M, Bayer EA, Shoham Y: Expression, purification and characterization of the cellulose-binding domain of the scaffoldin subunit from the cellulosome of clostridium thermocellum. Appl Environ Microbiol 1995, 61:1980-1986.

34. Barak Y, Handelsman T, Nakar D, Mechaly A, Lamed R, Shoham Y, Bayer EA Matching fusion-protein systems for affinity analysis of two interacting families of proteins: the cohesin-dockerin interaction. J Mol Recognit 2005, 18:491-501. 
35. Vazana Y, Moraïs S, Barak Y, Lamed R, Bayer EA: Designer cellulosomes for enhanced hydrolysis of cellulosic substrates. Methods Enzymol 2012, 510:429-452.

36. Irwin DC, Spezio M, Walker LP, Wilson DB: Activity studies of eight purified cellulases: specificity, synergism, and binding domain effects. Biotechnol Bioeng 1993, 42:1002-1013.

37. Ko KC, Han Y, Choi JH, Kim GJ, Lee SG, Song JJ: A novel bifunctional endo-/exo-type cellulase from an anaerobic ruminal bacterium. Appl Microbiol Biotechnol 2011, 89:1453-1462.

38. Gibbs MD, Reeves RA, Farrington GK, Anderson P, Williams DP, Bergquist PL: Multidomain and multifunctional glycosyl hydrolases from the extreme thermophile caldicellulosiruptor isolate Tok7B.1. Curr Microbiol 2000, 40:333-340.

39. Mingardon F, Chanal A, Tardif C, Bayer EA, Fierobe H-P: Exploration of new geometries in cellulosome-like chimeras. Appl Environ Microbiol 2007, 73:7138-7149

40. Berger E, Zhang D, Zverlov W, Schwarz WH: Two noncellulosomal cellulases of clostridium thermocellum, Cel91 and Cel48Y, hydrolyse crystalline cellulose synergistically. FEMS Microbiol Lett 2007, 268:194-201.

41. Boisset C, Fraschini C, Schulein M, Henrissat B, Chanzy H: Imaging the enzymatic digestion of bacterial cellulose ribbons reveals the endo character of the cellobiohydrolase Cel6A from humicola insolens and its mode of synergy with cellobiohydrolase Cel7A. Appl Environ Microbiol 2000, 66:1444-1452.

42. Boisset C, Petrequin C, Chanzy H, Henrissat B, Schulein M: Optimized mixtures of recombinant Humicola insolens cellulases for the biodegradation of crystalline cellulose. Biotechnol Bioeng 2001, 72:339-345.

43. Irwin D, Walker L, Spezio M, Wilson D: Activity studies of eight purified cellulases: specificity, synergism, and binding domain effects. Biotechnol Bioeng 1993, 42:1002-1013.

44. Walker $L P$, Belair $C D$, Wilson $D B$, Irwin DC: Engineering cellulase mixtures by varying the mole fraction of thermomonospora fusca $E_{5}$ and $E_{3}$, trichoderma reesei $\mathrm{CBH}$, and caldocellum saccharolyticum $\beta$-glucosidase. Biotechnol Bioeng 1993, 42:1019-1028

45. Doi RH, Park JS, Liu CC, Malburg LM, Tamaru Y, Ichiishi A, Ibrahim A: Cellulosome and noncellulosomal cellulases of clostridium cellulovorans. Extremophiles 1998, 2:53-60.

46. Flint HJ, Martin J, McPherson CA, Daniel AS, Zhang JX: A bifunctional enzyme, with separate xylanase and beta(1,3-1,4)-glucanase domains, encoded by the xynD gene of Ruminococcus flavefaciens. J Bacteriol 1993, 175:2943-2951.

47. Han SO, Cho HY, Yukawa H, Inui M, Doi RH: Regulation of expression of cellulosomes and noncellulosomal (hemi)cellulolytic enzymes in clostridium cellulovorans during growth on different carbon sources. I Bacteriol 2004, 186:4218-4227.

48. Kosugi A, Murashima K, Doi RH: Characterization of two noncellulosomal subunits, ArfA and BgaA, from clostridium cellulovorans that cooperate with the cellulosome in plant cell wall degradation. J Bacteriol 2002, 184:6859-6865.

49. Haimovitz R, Barak Y, Morag E, Voronov-Goldman M, Lamed R, Bayer EA: Cohesin-dockerin microarray: diverse specificities between two complementary families of interacting protein modules. Proteomics 2008, 8:968-979.

50. Miller GL: Use of dinitrosalicylic acid reagent for determination of reducing sugar. Anal Biochem 1959, 31:426-428.

doi:10.1186/1754-6834-5-78

Cite this article as: Morails et al:: Paradigmatic status of an endo- and exoglucanase and its effect on crystalline cellulose degradation. Biotechnology for Biofuels 2012 5:78.

\section{Submit your next manuscript to BioMed Central and take full advantage of:}

- Convenient online submission

- Thorough peer review

- No space constraints or color figure charges

- Immediate publication on acceptance

- Inclusion in PubMed, CAS, Scopus and Google Scholar

- Research which is freely available for redistribution

Submit your manuscript at www.biomedcentral.com/submit 